\title{
Paper
}

\section{Steroid diffusion into the navicular bursa occurs in horses affected by palmar foot pain}

\author{
J. M. Manfredi, M. Boyce, E. D. Malone, C. Anderson, L. B. Anderson, T. N. Trumble
}

Palmar foot pain is frequently treated by steroid injections into the distal interphalangeal
joint (DIPJ) in the anticipation that the steroid will diffuse to the navicular bursa and palmar
foot structures. The object of this study was to determine if triamcinolone acetonide (TA)
would in fact be able to locally diffuse from the DIPJ into the navicular bursa in horses
affected by palmar foot pain. Both forelimb DIPJs (nine horses) were injected with $10 \mathrm{mg}$ of
TA. Navicular bursa fluid samples, both forelimb and one hind limb (systemic control), were
analysed for TA with high-performance liquid chromatography/tandem mass spectrometry
(HPLC-MS/MS) six hours later. Foot radiographs were graded (0-4) on severity of changes.
Forelimb navicular bursa TA concentrations (mean \pm sd $\left.\log _{10}, 3.20 \pm 0.56\right)$ were significantly
higher than systemic control concentrations (mean \pm sd $\left.\log _{10}, 1.89 \pm 0.3\right)(\mathrm{P}<0.0001)$. Horses
with a radiographic grade of $>2$ were four times as likely to have TA log ${ }_{10}$ concentrations less
than 3.2 (158.49 ng/mI). TA locally diffused from the DIPJ into the navicular bursa in horses
affected by palmar foot pain; TA concentrations decreased as radiographic severity increased.

\section{Introduction}

Palmar foot pain is a common cause of lameness in performance horses and is described as pain localised to the heel region due to various pathologies of bone and/or soft tissues (Dyson and others 2005, Gutierrez-Nibeyro and others 2010, Stashak 2002). Medical treatment of palmar foot pain has been shown to clinically improve some horses for 2-9 months at a time, with 39.3 per cent of horses returning to work after three months (Gutierrez-Nibeyro and others 2010). Medical treatments include one or more of the following: oral nonsteroidal anti-inflammatory agents, shoeing changes, stall rest, bisphosphonates (tiludronate), and steroid injections of either the distal interphalangeal joint (DIPJ) or navicular bursa (Dabareiner and Carter 2003, Dabareiner and others 2003, Denoix and others 2003, Dyson and others 2005, Schoonover and others 2005, Sherlock and others 2007, Bell and others 2009, Gutierrez-Nibeyro and others 2010, Stashak 2002). Injections directly into the navicular bursa are technically challenging and often require additional equipment (radiography or ultrasonography) to ensure correct needle placement (Dabareiner and others 2003, Boyce and others 2010).

Due to the difficulty of navicular bursal injections, steroid injection of the DIPJ has been used as an indirect treatment for palmar foot pain (Dabareiner and Carter 2003, Gutierrez-Nibeyro and others 2010). In normal horses, it has been shown that triamcinolone acetonide (TA) injected into the DIPJ locally diffuses into the navicular

Veterinary Record (2012)

\section{J. M. Manfredi, DVM,}

M. Boyce, DVM, PhD,

E. D. Malone, DVM, PhD, DACVS,

C. Anderson, BS,

T. N. Trumble, DVM, PhD, DACVS,

Veterinary Population Department, University of Minnesota, 1365 Gortner Ave, St Paul, MN 55108, USA

L. B. Anderson, $\mathrm{PhD}$,

The Biochemistry, Molecular Biology, and Biophysics Department, University

bursa in amounts significantly greater than systemic diffusion alone (Pauwels and others 2008, Boyce and others 2010). Some horses affected by palmar foot pain have been reported to be refractory to steroid treatment of the DIPJ, only responding to steroid injections of the navicular bursa (Dabareiner and others 2003), possibly due to poor diffusion between the two synovial areas. Any bone or soft tissue change in the navicular region may alter how well TA locally diffuses through the tissue from the DIPJ into the navicular bursa. In horses with palmar foot pain, imaging techniques have been used to identify these changes, including navicular bone remodelling, enthesiophyte production, distal border fragments, dystrophic mineralisation of soft tissues, deep digital flexor tendonitis and adhesions, impar ligament injury and adhesions, and collateral sesamoidean ligament injury (Blunden and others 2009, Biggi and Dyson 2010). TA concentrations in the navicular bursa of horses affected with palmar foot pain have not been measured after DIPJ injections. This is important to examine because there is the potential that bone and/or soft tissue lesions associated with palmar foot pain may affect diffusion of the steroid from the DIPJ to the navicular bursa, and extrapolations from normal horses should not be presumed to be valid in those with disease.

The objective of this study was to assess if TA was present, and if so, in what amount in forelimb navicular bursae of horses affected by palmar foot pain after injection of TA into the DIPJ. We hypothesised that there would be local diffusion of TA from the DIPJ into the navicular bursa, and that horses with increased radiographic changes to the navicular bone would have less diffusion.

doi: 10.1136/vr.101075

of Minnesota, 321 Church St,

Minneapolis, MN55455, USA;

E-mail for correspondence:

e-mail:manfred1@msu.edu

Presented in part in poster form at the American College of Veterinary Surgeons Symposium, Seattle, Washington, October 2010.

Accepted October 10, 2012

\section{Materials and methods}

Nine mature Quarter Horses (mean age 11 years; range 4-20 years; four geldings, five mares) met the inclusion criteria for this study, which included that horses be affected by palmar foot pain, have a positive response to bilateral forelimb palmar digital nerve blocks, and have radiographic changes to the navicular bone. Horses enrolled were either clinical cases $(\mathrm{N}=2)$, a university-owned teaching horse $(\mathrm{N}=1)$ or horses recruited from a local sales barn $(\mathrm{N}=6)$. In all cases, the owners agreed to have their animals participate in this experimental study. All procedures and the use of horses were approved by the Institutional Animal Care and Use Committee. 
A thorough musculoskeletal exam was performed on all horses, including hoof tester examination, limb palpation and palmar digital nerve blocks. All horses demonstrated a positive pain response to hoof testers across the heels and across the central third of the frog. No palpable effusion or pain was located in any other location in the forelimbs, other than mild coffin-joint effusion palpated bilaterally in one horse. Lameness was subjectively evaluated by a clinician experienced in lameness examination, at the trot on firm ground, on a straight line, and while circling in both directions (JMM). American Association of Equine Practicioners lameness grades were assigned (all horses were a grade 2-3/5) (Swanson 1984), and a palmar digital nerve block was performed on the forelimb that was most lame with $1.5 \mathrm{mls}$ of mepivicaine at each site. Horses were examined at five minutes postadministration of the palmar digital nerve block, and all horses switched lameness to the contralateral forelimb (grade $2-3 / 5$ on the contralateral forelimb). A palmar digital nerve block was performed on that limb, and the horse was examined again after five minutes. All horses significantly improved in lameness after the bilateral palmar digital nerve blocks were performed. Therefore, based on the description in previous studies (Murray and others 2006, Bell and others 2009, Sampson and others 2009), nine horses were considered to have palmar foot pain since they had a positive response to palmar digital nerve blocks.

\section{Radiographs}

A radiographic series of the navicular bone region (lateromedial, dorsopalmar, $60^{\circ}$ dorsoproximal-palmarodistal oblique and palmaroproximal-palmarodistal views) of both forelimbs was performed to assess the presence of radiographic changes in the navicular region. Radiographic findings of the navicular bone were assigned a grade according to a previously reported scale (Dyson 2008). Briefly, a score of 0 indicated an excellent condition of the navicular bone. A score of 1 indicated a good condition of the navicular bone, with distal border lucencies of more variable shapes. A score of 2 indicated a fair condition of the navicular bone, with sclerosis slightly obscuring the definition between the medulla and cortex, variably shaped lucencies along the distal and horizontal border, asymmetry between the navicular bones, and mild enthesophytosis. A score of 3 indicated a poor condition of the navicular bone, with poor corticomedullary definition, thickening of the cortices, many radiolucent zones along the borders, large enthesophytes and distal border fragments. A score of 4 indicated a bad condition of the navicular bone, with large cysts and large lucencies in, or new bone formation on the flexor cortex (Dyson 2008). Radiographs were reviewed by three of the authors (JMM, EDM and TNT) who were blinded to the horses' navicular bursal TA concentrations, and to the radiographic grade assigned to that foot by the other reviewers. Total grades were averaged, and then rounded for analyses. Only horses with a navicular radiographic grade of 1-4 (Dyson 2008), demonstrating radiographic changes to the navicular bone were included in this study.

\section{Sampling technique}

Horses were sedated with either xylazine hydrochloride (Anased, $100 \mathrm{mg} / \mathrm{ml}$, Lloyd Laboratories), $0.3-0.5 \mathrm{mg} / \mathrm{kg}$ intravenous, or detomidine (Dormosedan, $10 \mathrm{mg} / \mathrm{ml}$, Pfizer Animal Health), 0.01 $0.02 \mathrm{mg} / \mathrm{kg}$ intravenous. Both forelimbs of each horse were clipped circumferentially from the proximal pastern to the coronary band. Abaxial sesamoid nerve blocks with $3 \mathrm{ml}$ of mepivacaine (Carbocaine, $20 \mathrm{mg} / \mathrm{ml}$, Pfizer) per site were performed on both forelimbs to assist in obtaining synovial fluid and with TA injection. Both forelimbs were aseptically prepared for arthrocentesis of the DIPJ. Arthrocentesis was performed with an 18 gage, 1.5 inch needle to maximise fluid collection using a dorsal inclined approach (Gandini 2007). Synovial fluid was obtained without lavage, and $10 \mathrm{mg}$ of TA (Kenalog, $10 \mathrm{mg} / \mathrm{ml}$, Pharmacia \& Upjohn Co) and $1.25 \mathrm{ml}$ of Lactated Ringer's Solution were injected into each forelimb DIPJ. This combination of TA and Lactated Ringer's Solution was used to enable direct comparison with a previous study examining TA diffusion from the DIPJ into the navicular bursa in normal horses (Boyce and others 2010).

In normal horses (Boyce and others 2010), the highest navicular bursal TA concentration from diffusion occurred six hours after
DIPJ injection of TA. Therefore, at six hours post-DIPJ injection, horses in our study were again sedated and abaxial sesamoid nerve blocks were performed on both forelimbs, which were then aseptically prepared for fluid collection from the navicular bursa of both forelimbs. In addition, one hind limb was randomly chosen as the systemic control, since TA can only arrive at the hind limb via the blood stream. That hind limb was clipped, an abaxial sesamoid nerve block performed, and it was aseptically prepared from the plantaroproximal aspect of the pastern to the coronary band to facilitate navicular bursal fluid collection. For navicular bursal samples, feet were elevated by placing both forefeet on four-inch blocks and navicular bursal fluid was obtained with an 18 gage, 3.5 inch spinal needle placed just above the heel bulbs on midline. The needle was aimed in a sagittal plane towards a point on the coronary band halfway between the most dorsal and palmar aspects of the coronary band (Boyce and others 2010). This varied slightly from the reported distal palmar approach to the navicular bursa (Piccot-Crezollet and others 2005) in that we did not aim for a location $1 \mathrm{~cm}$ below the coronary band because we found the needle to be placed too distally for adequate fluid collection. The needle was advanced until it contacted bone and a lateral radiograph was obtained to check for correct needle positioning where it contacted the navicular bone in the mid- to proximal third of its flexor surface. Fluid was obtained from the bursa either while the hoof was weight bearing or when the hoof was elevated and flexed. On two horses, navicular bursa samples from one individual forelimb required lavage in order to obtain samples so these two limbs were excluded from further analysis since we felt the dilution would affect our ability to compare all the samples. Systemic control samples were similarly obtained with the exception that the hind fetlock was flexed with the toe touching the ground instead of the foot being flat on a block at the time of needle placement.

Similar to a previous study, (Boyce and others 2010) $1 \mathrm{ml}$ of omnipaque (GE Healthcare Inc), $125 \mathrm{mg}$ of amikacin (Amikacin, $250 \mathrm{mg}$ / $\mathrm{ml}$, Bedford Laboratories) and $1.5 \mathrm{ml}$ of Lactated Ringer's Solution were injected into the bursa immediately after obtaining fluid, and a lateral or flexed lateral (depending on how fluid was obtained) radiograph was taken to confirm needle placement in the bursa, and to ensure that there was no direct communication between the DIPJ and the navicular bursa. Amikacin was injected into the navicular bursa at the authors' preference after bursal samples were obtained to help prevent possible complications associated with arthrocentesis. All bursal fluid samples were free of gross blood contamination and were frozen in cryovials at $-80^{\circ} \mathrm{C}$ until extraction and analysis could be performed.

\section{Extraction and analysis}

Extraction and analysis of the fluid was performed similarly to that of a previous study (Boyce and others 2010), with the exception that DIPJ synovial fluid samples obtained prior to TA injection were analysed for the presence of TA independently. Briefly, a 4000 OTRAP mass spectrometer was used for analysis. A standard curve was determined using triamcinolone- $6 \mathrm{~d}_{1}$ Acetonide- $\mathrm{d}_{6}(\mathrm{TAC})$ as the internal standard. Samples were thawed on ice. TAC (10 ng) was added to $10 \mu \mathrm{l}$ of sample prior to extraction of TA using ethyl acetate. The ethyl acetate aliquots containing TA and TAC were dried in a speed vacu$\mathrm{um}$, and the TA was rehydrated with $75 \mu \mathrm{l}$ of a load buffer. Samples were stored at $-20^{\circ} \mathrm{C}$ until high-performance liquid chromatography/ tandem mass spectrometry (HPLC-MS/MS) analysis could be performed. Reversed-phase HPLC-MS/MS was performed and data were collected with dedicated software (Analyst 1.5; ABSCIEX, Foster City, California, USA). For TA, the mass transitions monitored were 435.2 to 397.1, and for TAC, ion transitions monitored were 442.2 to 404.1, where 435.2 and 442.2 are the precursor ion masses for the parent compounds. For quantitative purposes, the peak areas under 397.1 and 404.1 were used (MultiQuant 2.0.2; ABSCIEX, Foster City, California, USA). Amounts of TA present in the bursal fluid were determined from the ratio of the area of TA to TAC since the amount of internal standard is known. A signal-to-noise $(\mathrm{S}: \mathrm{N})$ ratio of 10 was used on all of the samples for which an $\mathrm{ng} / \mathrm{ml}$ concentration was indicated. The limit of quantification was $0.01 \mathrm{ng} / \mathrm{ml}$; all samples in the study were well above that amount. 


\section{Statistical analysis}

Normality of the TA bursal concentrations was assessed with the Shapiro-Wilk normality test. Fore and hind navicular bursal TA concentrations required log transformation of the data to obtain normality. Mean TA concentrations between fore and hind limb (systemic control) bursal fluid concentrations within affected horses were compared using unpaired t tests with Welch's correction. Correlation between the TA concentrations and the radiographic grade, as well as TA concentration and age were determined using a Spearman correlation coefficient. A Fisher's Exact Test was used to calculate the association (sensitivity, specificity, and likelihood ratio) between total radiographic grade $(>2)$ and $\log _{10}$ TA concentration $<3.2$ (untransformed $<158.49 \mathrm{ng} / \mathrm{ml}$ ); the median. Inter-rater radiographic scoring reliability of the navicular grading was analysed with an average measure intraclass correlation coefficient. Posthoc power analyses were performed (GraphPad StateMate 2.00, GraphPad Software, Inc, California, USA). Statistics were carried out with dedicated software (SPSS, IBM, Chicago, Illinois, USA; GraphPad InStat, GraphPad Software, Inc, California, USA). Significance was set at $\mathrm{P} \leq 0.05$ for all analyses.

\section{Results}

TA was present in detectable amounts in all navicular bursal fluid samples. Contrast bursography demonstrated no direct communication between the navicular bursa and the DIPJ in any of the horses in this study. No TA was present in any of the pretreatment DIPJ synovial fluid samples. Forelimb navicular bursae TA $\log _{10}$ concentrations (mean \pm sd, 3.20 \pm 0.56 ; median $=3.2$; untransformed mean and median $158.49 \mathrm{ng} / \mathrm{ml}$ ) were significantly higher $(\mathrm{P}<0.0001)$ than hind limb TA $\log _{10}$ navicular bursae concentrations used as systemic controls (mean \pm sd, 1.89 \pm 0.3 ; untransformed mean $7.76 \mathrm{ng} /$ ml) (Table 1). Post-hoc power analysis of whether TA would locally diffuse into the bursa versus coming from systemic circulation alone was 99 per cent. TA $\log _{10}$ concentrations had a trend towards a linear association with radiographic grade $(\mathrm{R}=0.441, \mathrm{P}=0.087)$, but radiographic grade did not have a significant linear correlation with age $(R=0.025, P=0.926)$. However, there was a significant association $(\mathrm{P}<0.04)$ between the assigned radiographic grade and TA concentrations; limbs in which the assigned radiographic grade was $>2$, were four times as likely to be associated with lower TA $\log _{10}$ concentrations $(<3.2)$. The average measure intraclass correlation coefficient for agreement of the observers' radiographic scores was 0.891 . Posthoc power analysis of whether a linear correlation between increasing radiographic grade and TA concentrations could be determined was 99 per cent.

\section{Discussion}

Diffusion occurred in horses affected with palmar foot pain, despite the presence of pathology in the region. This local diffusion occurred similar to previous studies on normal horses (Pauwels and others 2008, Boyce and others 2010), since horses affected by palmar foot pain had significantly higher TA concentrations present in the forelimb navicular bursae than in the hind limb systemic control samples, while bursography demonstrated the lack of direct communication between the DIPJ and forelimb navicular bursae. This study also suggests that greater navicular bone pathology as represented by a higher radiographic grade may affect the amount of TA diffusion. Any decrease in this diffusion because of bone or soft tissue pathology may partly explain why some horses can be unresponsive to steroid injection of the DIPJ, requiring direct bursal injections to achieve clinical effect (Dabareiner and others 2003).

Forelimb navicular bursae TA concentrations after DIPJ injection were lower in palmar foot pain horses when compared with normal horses examined by Boyce and others (2010), but were greater than normal horses examined by Pauwels and others (2008). We directly measured TA concentrations in the current study using the same techniques reported by Boyce and others (2010); whereas, Pauwels and others (2008) measured the presence of a TA metabolite. Therefore, since the concentration of the TA metabolites should be lower, comparison of concentrations between our study and Pauwels' are difficult to make. However, when directly comparing our results to those from normal horses reported by Boyce and others (2010) (mean=918.3 ng/ $\mathrm{ml}$ ), it appears that less TA was able to diffuse locally from the DIPJ to the navicular bursa in our horses affected by palmar foot pain (mean $158.49 \mathrm{ng} / \mathrm{ml}$ ). This is further supported by the fact that the hind limb (systemic control) TA concentrations were similar between the two studies (mean $4.1 \mathrm{ng} / \mathrm{ml}$ (Boyce and others 2010) and mean $7.76 \mathrm{ng} /$ $\mathrm{ml}$ ). Diffusion of TA can be affected by several variables, such as: tissue miscibility, temperature, time allowed for diffusion, fluid viscosity, surface area, molecule size, inflammation and ionic mobility (Dryll and others 1977, Callister 2000, Leddy 2008). The ease of diffusion of TA through the interstitial space between the DIPJ and navicular bursa is unknown in healthy horses, much less in those with pathology. Site compression that could result from remodelling of the navicular bone or poor hoof pastern axis could result in inappropriate uneven loading that has the potential to delay local diffusion (Leddy 2008). In addition, bony remodelling could also result in a decreased surface area for diffusion, thus slowing the rate of diffusion according to Fick's law (Fick 1855, Callister 2000, Leddy 2008). Obtaining TA navicular bursal concentrations at later time points in our study may have elucidated whether diffusion was decreased or just slowed in the cases

\begin{tabular}{|c|c|c|c|c|c|}
\hline Horse & $\begin{array}{l}\text { Hind limb } \\
\text { sampled }\end{array}$ & $\begin{array}{l}\text { Systemic control (TA } \\
\log _{10} \text { concentration) }\end{array}$ & $\begin{array}{l}\text { Forelimb } \\
\text { sampled }\end{array}$ & $\begin{array}{l}\text { Forelimb bursae (TA } \\
\log _{10} \text { concentration) }\end{array}$ & $\begin{array}{l}\text { Mean radiographic } \\
\text { grade }(0-4)\end{array}$ \\
\hline \multirow[t]{2}{*}{1} & \multirow[t]{2}{*}{ LH } & \multirow[t]{2}{*}{1.34} & $\mathrm{LF}$ & 3.57 & 2 \\
\hline & & & RF & 3.62 & 2 \\
\hline \multirow[t]{2}{*}{2} & \multirow[t]{2}{*}{$\mathrm{LH}$} & \multirow[t]{2}{*}{1.82} & LF & - & - \\
\hline & & & RF & 1.99 & 3 \\
\hline \multirow[t]{2}{*}{3} & \multirow[t]{2}{*}{ RH } & \multirow[t]{2}{*}{1.79} & LF & 2.54 & 1 \\
\hline & & & RF & 3.58 & 1 \\
\hline \multirow[t]{2}{*}{4} & \multirow[t]{2}{*}{ LH } & \multirow[t]{2}{*}{1.88} & LF & 3.12 & 3 \\
\hline & & & RF & 3.26 & 3 \\
\hline \multirow[t]{2}{*}{5} & \multirow[t]{2}{*}{ LH } & \multirow[t]{2}{*}{1.95} & LF & 3.78 & 2 \\
\hline & & & $\mathrm{RF}$ & 3.73 & 2 \\
\hline \multirow[t]{2}{*}{6} & \multirow[t]{2}{*}{ LH } & \multirow[t]{2}{*}{2.52} & LF & - & - \\
\hline & & & RF & 3.88 & 2 \\
\hline \multirow[t]{2}{*}{7} & \multirow[t]{2}{*}{$\mathrm{RH}$} & \multirow[t]{2}{*}{1.85} & LF & 3.15 & 3 \\
\hline & & & RF & 2.54 & 3 \\
\hline \multirow[t]{2}{*}{8} & \multirow[t]{2}{*}{ LH } & \multirow[t]{2}{*}{1.88} & LF & 3.82 & 2 \\
\hline & & & $\mathrm{RF}$ & 2.85 & 3 \\
\hline \multirow[t]{2}{*}{9} & \multirow[t]{3}{*}{ RH } & \multirow[t]{2}{*}{2.01} & LF & 3.19 & 3 \\
\hline & & & RF & 2.60 & 2 \\
\hline Meantsd & & $1.89 \pm 0.30$ & & $3.20 \pm 0.56$ & \\
\hline
\end{tabular}


with palmar foot pain as compared with normal horses. However, to what degree the TA was diffusing into the navicular bursa versus the interstitial tissues or capillaries would still be unknown. Regardless, it appears that pathological changes associated with palmar foot pain may limit the amount of local diffusion of TA from the DIPJ to the navicular bursa.

One of the most commonly used methods to evaluate the amount and severity of pathology of the navicular region is radiographic evaluation. Since the advent of MRI, more detailed analysis of bone and soft tissue pathology associated with palmar foot pain has been outlined (Murray and others 2006, Blunden and others 2009, Sampson and others 2009, Gutierrez-Nibeyro and others 2010). However, since radiographs remain the mainstay of what is used to guide therapy in the field, we chose to examine radiographic changes of the navicular region to see if there was an obvious correlation between the radiographic findings of the navicular bone and TA concentrations in the navicular bursa. If differences in the navicular bursa TA concentrations after injection into the DIPJ could be identified using radiographs alone, it might help guide practitioners towards different medical therapies, such as direct bursal injection versus DIPJ injection.

We were able to identify a trend $(\mathrm{P}<0.1)$ towards a linear correlation between the total radiographic grade and the TA concentrations in the navicular bursae. The fact that it is only a trend is likely due to clinical variability, and the fact that different pathology may affect diffusion differently; however, posthoc statistical power for detecting a linear relationship was 99 per cent. There was good agreement between observers when assigning radiographic grade, but it is important to note that the statistic used (unlike Kappa) does not take chance agreement by the raters into account, so agreement may be slightly inflated. There was a significant association between limbs with a higher assigned radiographic grade of the navicular bone and lower TA $\log _{10}$ concentrations $(\mathrm{P}<0.04)$. Specifically, limbs in which the assigned radiographic grade was $>2$ were four times as likely to be associated with TA $\log _{10}$ concentrations of $<3.2$ (median concentration; untransformed $158.49 \mathrm{ng} / \mathrm{ml}$ ) than limbs with a total navicular radiographic grade $\leq 2$. This demonstrated that once radiographic findings of the navicular bone became poor to bad (grades 3 and 4, respectively; the top half of the grading scale) (Dyson 2008), a significant number of samples had less TA diffusion (in the bottom half of the reported TA forelimb bursal concentrations) into the navicular bursa than those with assigned radiographic grades of good to fair (grades 1 and 2, respectively, lower half of the grading scale) (Dyson 2008). This may suggest that greater severity of radiographic changes to the navicular bone may affect the ability of TA to diffuse from the DIPJ to the navicular bursa. This decreased diffusion may be directly related to the bony changes, or there may be soft tissue changes that affect diffusion between the joint and the navicular bursa. Not having MRI analysis of the forelimbs was a limitation of our study; therefore, to understand the soft tissue contribution better, further paired radiographic and MRI studies of palmar foot pain horses should be analysed in conjunction with TA measurements from the bursa postTA DIPJ injection to further delineate which types of lesions are most likely to hamper diffusion.

Age and breed can have potential effects on the radiographic findings in the navicular region. Animals with increasing age have been shown to have increasing numbers of radiographic and/or histologic changes associated with the navicular bone in some studies (Wright and others 1998, Dik and others 2001) but not in others (Murray and others 2006, Bell and others 2009). In the present study, no linear correlation or other associations between age and radiographic grade were identified. Radiographic variations of normal navicular bone architecture may exist between breeds. For example, Warmbloods may have a variable navicular bone shape with little associated clinical lameness. However, to the authors' knowledge, similar radiographic variations have not been reported in Quarter Horses. Exclusively Quarter Horses were chosen for the current study since many studies currently published in this area of research contain a large number of Quarter Horses or Paints (Dabareiner and others 2003, Pauwels and others 2008, Bell and others 2009). It is possible that Quarter Horses may have a lower amount of normal diffusion between the DIPJ and the navicular bursa than horses of other breeds, since multiple breeds were used in the previous study of normal horses (Boyce and others 2010). However, the variability of the TA concentrations in the Boyce and others (2010) study were low, making it more likely that the differences in TA concentration in our study is due to pathology of the distal limb related to palmar foot pain.

Horses that present with palmar foot pain may also have DIPJ effusion (Stashak 2002). This may relate to the presence of DIPJ osteoarthritis, or may be secondary to hoof conformation. A negative response to intrasynovial anaesthesia of the DIPJ would have offered further support of the diagnosis of palmar foot pain. However, a positive response could have indicated pain originating from the DIPJ itself (especially if it occurred within a few minutes of the block), or, as anaesthetics do diffuse out of the joint into the bursal region over time (Bowker and others 1996, Pleasant and others 1997), pain originating from the navicular and palmar foot region. Local anaesthetics also have the potential to alter the diffusion of other injected drugs (eg, TA). In this study, we elected to avoid the added complexity. Additionally, in our study, there was only one horse (number 4) that had mild DIPJ effusion. No other horses had any clinical signs of effusion, and minimal or no radiographic changes were present in the DIPJ, making it unlikely that DIPJ osteoarthritis or inflammation caused the lamenesses or affected TA diffusion. Steroids administered into the DIPJ in the face of effusion may allow for diffusion into the navicular bursa while also helping to resolve any inflammation and secondary pain originating from the DIPJ itself to improve performance. Future comparative studies of inflammatory mediators present in both the DIPJ and navicular bursa in horses with palmar foot pain may be able to elucidate what degree of changes in the DIPJ may impact treatment.

It is unknown whether it is TA or one of its metabolites that is clinically active in the joint or bursa, and what concentration is needed to be clinically effective. Therefore, we are unable to tell if the concentrations of TA $<3.2 \log _{10}(<158.49 \mathrm{ng} / \mathrm{ml})$ in the navicular bursae associated with higher assigned radiographic grades are capable of achieving a clinical effect. Based on one study (Kantrowitz and others 1975), a TA concentration of $37 \mathrm{ng} / \mathrm{ml}$ was extrapolated from in vitro studies to be the therapeutically effective TA concentration; however, this remains unproven in vivo. In the present study, DIPJ injection with $10 \mathrm{mg}$ of TA garnered a variety of concentrations within the navicular bursa, but most concentrations were higher than the above extrapolated value $(37 \mathrm{ng} / \mathrm{ml})$. Conclusive commentary about the TA bursal concentrations that are needed to achieve clinical response is beyond the scope of the research presented in the current study as we were unable to follow all of these horses out over time.

Quarter Horses with palmar foot pain had TA locally diffuse into the forelimb navicular bursae after injection into the DIPJ. Horses with palmar foot pain may benefit from TA injection into the DIPJ, though horses with increasing radiographic severity of changes to the navicular bone (grade 3-4 out of 4) may have less TA diffuse to the affected region.

\section{Acknowledgements}

This work was supported by a grant from the American Quarter Horse Foundation.

Provenance: Not commissioned; externally peer reviewed

\section{References}

BELL, C. D., HOWARD, R. D., TAYLOR, D. S., VOSS, E. D. \& WERPY, N. M. (2009) Outcomes of podotrochlear (navicular) bursa injections for signs of foot pain in horses evaluated via magnetic resonance imaging: 23 cases (2005-2007). Journal of the American Veterinary Medical Association 234, 920-925

BIGGI, M. \& DYSON, S. (2010) Comparison between radiological and magnetic resonance imaging lesions in the distal border of the navicular bone with particular refer ence to distal border fragments and osseous cyst-like lesions. Equine Veterinary Journal $42,707-712$

BLUNDEN, A., MURRAY, R. \& DYSON, S. (2009) Lesions of the deep digital flexor tendon in the digit: a correlative MRI and post mortem study in control and lame horses. Equine Veterinary Journal 41, 25-33

BOWKER, R.M., LINDER, K., KIMBERLY, R., VANWULFER, P. \& OCELLO, P. J. (1996) Distribution of local anesthetic injected into the distal interphalangeal joint and podotrochlear bursa: an experimental study. Pferdeheikunde 12, 609-612

BOYCE, M., MALONE, E. D., ANDERSON, L. B., PARK, S., GODDEN, S. M. JENNER, F. \& TRUMBLE, T. N. (2010) Evaluation of diffusion of triamcinolone 
acetonide from the distal interphalangeal joint into the navicular bursa in horses. American Journal of Veterinary Research 71, 169-175

CALLISTER, W. D., JR (2000) Materials Science and Engineering an Introduction. New York: John Wiley \& Sons, Inc.

DABAREINER, R. M. \& CARTER, G. K. (2003) Diagnosis, treatment, and farriery for horses with chronic heel pain. The Veterinary Clinics of North America Equine Practice 19 417-441

DABAREINER, R. M., CARTER, G. K. \& HONNAS, C. M. (2003) Injection of corticosteroids, hyaluronate, and amikacin into the navicular bursa in horses with signs of navicular area pain unresponsive to other treatments: 25 cases (1999-2002). Journal of the American Veterinary Medical Association 223, 1469-1474

DENOIX, J. M., THIBAUD, D. \& RICCIO, B. (2003) Tiludronate as a new therapeutic agent in the treatment of navicular disease: a double-blind placebo-controlled clinical trial. Equine Veterinary Journal 35, 407-413

DIK, K. J., VAN DEN BELT, A. J. \& VAN DEN BROEK, J. (2001) Relationships of age and shape of the navicular bone to the development of navicular disease: a radiological study. Equine Veterinary Journal 33, 172-175

DRYLL, A., LANSAMAN, J., CAZALIS, P., PELTIER, A. P. \& DE SEZE, S. (1977) Light and electron microscopy study of capillaries in normal and inflammatory human synovial membrane. Journal of Clinical Pathology 30, 556-562

DYSON, S. (2008) Radiological interpretation of the navicular bone. Equine Veteinary Education 20, 268-280

DYSON, S. J., MURRAY, R. \& SCHRAMME, M. C. (2005) Lameness associated with foot pain: results of magnetic resonance imaging in 199 horses (January 2001-December 2003) and response to treatment. Equine Veterinary Journal 37, $113-121$

FICK, A. (1855) On liquid diffusion. Philosophical Magazine and Journal of Science 10, 31-39

GANDINI, M. (2007) Comparison of three dorsal techniques for arthrocentesis of the distal interphalangeal joint in horses. Journal of the American Veterinary Medical Association 231, 254-258

GUTIERREZ-NIBEYRO, S. D., WHITE II, N. A. \& WERPY, N. M. (2010) Outcome of medical treatment for horses with foot pain: 56 cases. Equine Veterinary Journal 42 680-685
KANTROWITZ, F, ROBINSON, D. R., MCGUIRE, M. B. \& LEVINE, L. (1975) Corticosteroids inhibit prostaglandin production by rheumatiod synovia. Nature 258 , 737-739

LEDDY HA, G. F. (2008) Site-specific effects of compression on macromolecular diffusion in articular cartilage. Biophysical Journal 95, 4890-4895

MURRAY, R. C., SCHRAMME, M. C., DYSON, S. J., BRANCH, M. V. \& BLUNDEN, T. S. (2006) Magnetic resonance imaging characteristics of the foot in horses with palmar foot pain and control horses. Veterinary Radiology \& Ultrasound 47, 1-16

PAUWELS, F. E., SCHUMACHER, J., CASTRO, F. A., HOLDER, T. E., CARROLL R. C., SEGA, G. A. \& ROGERS, C. W. (2008) Evaluation of the diffusion of corticosteroids between the distal interphalangeal joint and navicular bursa in horses. American Journal of Veterinary Research 69, 611-616

PICCOT-CREZOLLET, C., CAUVIN, E. R. \& LEPAGE, O. M. (2005) Comparison of two techniques for injection of the podotrochlear bursa in horses. Journal of the American Veterinary Medical Association 226, 1524-1528

PLEASANT, R.S., MOLL, H. D., LEY, W. B., LESSARD, P. \& WARNICK, L.D. (1997) Intra-articular anesthesia of the distal interphalangeal joint alleviates lameness associated with the navicular bursa in horses. Veterinary Surgery 26(2), 137-140

SAMPSON, S. N., SCHNEIDER, R. K., GAVIN, P. R., HO, C. P., TUCKER, R. L. \& CHARLES, E. M. (2009) Magnetic resonance imaging findings in horses with recent onset navicular syndrome but without radiographic abnormalities. Veterinary Radiology \& Ultrasound 50, 339-346

SCHOONOVER, M. J., JANN, H. W. \& BLAIK, M. A. (2005) Quantitative comparison of three commonly used treatments for navicular syndrome in horses. American Journal of Veterinary Research 66, 1247-1251

SHERLOCK, C. E., KINNS, J. \& MAIR, T. S. (2007) Evaluation of foot pain in the standing horse by magnetic resonance imaging. Veterinary Record 161, 739-744

STASHAK, T. (2002) Navicular syndrome. In: Adam's Lameness in Horses. Ed. T. Stashak. Lippencott Williams and Wilkins. pp 664-678

SWANSON, T. (1984) Guide for Veterinary Service and Judging of Equestrian Events. 3rd edn. Golden, CO: Am Assoc Eq Pract. p 24

WRIGHT, I. M., KIDD, L. \& THORP, B. H. (1998) Gross, histological and histomorphometric features of the navicular bone and related structures in the horse. Equine Veterinary Journal 30, 220-234 


\section{veterinary Steroid diffusion into the navicular bursa occurs in horses affected by palmar foot pain}

J. M. Manfredi, M. Boyce, E. D. Malone, et al.

Veterinary Record 2012 171: 642 originally published online November 7, 2012

doi: $10.1136 / v r .101075$

Updated information and services can be found at:

http://veterinaryrecord.bmj.com/content/171/25/642.full.html

These include:

References This article cites 25 articles, 2 of which can be accessed free at: http://veterinaryrecord.bmj.com/content/171/25/642.full.html\#ref-list-1

Email alerting Receive free email alerts when new articles cite this article. Sign up in service the box at the top right corner of the online article.

Notes

To request permissions go to:

http://group.bmj.com/group/rights-licensing/permissions

To order reprints go to:

http://journals.bmj.com/cgi/reprintform

To subscribe to BMJ go to:

http://group.bmj.com/subscribe/ 